\title{
Synergistic Interactions of Antimicrobials to Counteract the Drug-Resistant Microorganisms
}

\author{
Mohamed Juvad Najeer Ahamed ${ }^{1}$, Faridha Begum Ibrahim ${ }^{1}$, Hemalatha Srinivasan 1,* D \\ 1 School of Life Sciences, B.S. Abdur Rahman Crescent Institute of Science and Technology, Vandalur, Chennai-48, India \\ * Correspondence: hemalatha.sls@crescent.education;
}

Scopus Author ID 56895829300

Received: 22.02.2021; Revised: 5.04.2021; Accepted: 9.04.2021; Published: 26.04.2021

\begin{abstract}
The development of multiple drug resistance organisms (MDR) is a major threat, and due to this emergence, it is found that it is difficult to treat many infectious diseases. Synergistic interaction means combining existing antimicrobials with any component that says it can be a herbal compound, phytochemicals, essential oils, antibiotics, antimicrobial peptides, and even any other antimicrobial. With the help of antimicrobial and phytochemical blending, this effective resistance conversion will neutralize the resistance mechanism, which makes the drug effective in resistant organisms. Microbes have developed several strategies, such as efflux pump inhibitors or inhibition of drug degrading enzymes. This combination interaction has shown promising abatement in minimum inhibitory concentrations and upturn of susceptibility of drug-resistant microorganisms. This synergistic interaction is brought into play because it is very difficult to develop new antimicrobials. There are already only limited antimicrobials that are segregated into classes and cannot be used all the time. So this synergistic effect can bring about a change like it can be used to increase antimicrobials' effect and prevent resistance in the organisms. Thus, it might be helpful in the effective treatment against various infections.
\end{abstract}

Keywords: multiple drug-resistant organisms; synergistic effect; antimicrobial-resistant; phytochemicals.

(C) 2021 by the authors. This article is an open-access article distributed under the terms and conditions of the Creative Commons Attribution (CC BY) license (https://creativecommons.org/licenses/by/4.0/).

\section{Introduction}

Antimicrobial resistance is a major concern because it is important in treating deadly infections. Suppose this issue is not being taken care. In that case, it reduces our capability and limits the therapeutic options to control the diseases or infections. In the prior days, the advancement of antibiotics has had the option to control the microorganisms responsible for the infection or the disease. The very first discovered antibiotic was penicillin which Sir Alexander Fleming discovered. Upon discovering the antibiotics, he also mentioned the possibility of the chrysalis of the resistance in the organisms when it is under-dosed, and now it is being realized by the broad scale of audiences.

The drugs used to treat many infections, nearly all pathogenic infectious organisms to acquire the resistance. The main reasons that drive the development of antimicrobial resistance are that the overuse of antibiotics in many sectors, say in humans, is used for therapeutic purposes, and in food-producing animals, it is used as growth promoters and is also used in prophylaxis meaning which is a treatment option that prevents the animals from infections. Thus, there is a selection pressure in the microorganisms, making them gain resistance over a 
single drug or multiple drugs. This antimicrobial resistance is recognized through the nonclinical environment and the other factors, including exposure to pollutants and other environmental factors responsible for the spread of antimicrobial-resistant genes. However, these antibiotics or even the antimicrobials values are nearly getting down as it is used irrationally [1]. There are different elements that show the decrease of the adequacy of antitoxins because the uprising of insusceptible traded off people, maturing, relocate complexities, and even the pressure. For example, around $90-95 \%$ of S.aureus strains are impervious to penicillin, while $70-80 \%$ are impervious to methicillin.

Most of the resistance that appears in the organisms is due to excessive use, which leads to selection pressure. The capability of the organisms to resist the drug treatment is inherited, and as mentioned earlier, it can also be acquired, which is being transmitted from species to species using horizontal gene transfer. For instance, one of the obstruction systems is the alteration of the objective site, which the transformation has incited. That prompts the decline in the antimicrobial viability of the medication. Regular models may remember the basic change for the proteins like penicillin restricting proteins and DNA gyrase and RNA polymerase, making a few medications inert. Apart from the earlier belief of intrinsic development of resistance to the antimicrobials that were not exposed unveiled the resistance due to the matter of fact of the extracellular pump's presence, the efflux pump which siphons out the required supplements and as well the drugs. Thus, the bacteria develop resistance through the extracellular mediated efflux pump, target modification, and enzyme-mediated deterioration of drugs [2].

In its thick, the handiest method to counteract the drug resistance organisms is to codirect with the resistance rework along with the active drug. To help this, it has been clinically perceived that beta-lactamase inhibitors (sulbactam, clavulanic acid) are utilized in combination with amoxicillin [3].

Combination therapy of drugs can be categorized into three major types: synergistic, additive, and antagonistic. This review article's main focus would be on the synergistic interaction; in this approach, the combined agents say that an antimicrobial compound and a phytochemical compound tend to show a greater effect than the single use of the compound. Additivity is the interaction between two compounds that are commonly absolute to each other, thus being less effective. Finally, antagonism is the interaction between the drugs, which tend to have opposite effects, meaning that it may reduce the other drug's effect when used alone. The use of synergistic combinational therapy is the main focus because they tend to show more effectiveness of the drug, can prevent the resistance of drugs in the organisms when used against it, and it tends to treat the infections with the least effective dosage meaning that they can show low minimum inhibitory combinations [4]. The synergistic interactions are now being majorly studied along with phytochemicals and essential oils in combinations with the drugs or the antibiotic or the antimicrobial resistance, which appear to be promising treatments for future use. Thus this type of interaction can be used to treat infections that have beneficial values [5].

\section{Role of Natural Products in Antimicrobial Detection and its Synergistic Combination}

Natural extracts or phytochemicals are produced by the plants where they can be extracted from any part of the plant, say roots, stem, and leaves. These phytochemicals can be secondary metabolites. Usually, the phytochemicals have a small molecular weight, and 
generally, they have weaker antibiotic action than the antibiotic action alone. Hence, using the phytochemicals along with the already existing antibiotics in order to have effective synergistic interaction. The combinational therapy of synergism with an antibiotic and phytochemical establish the effectiveness of antibiotics and prevent the resistance in the organisms, and in such case, this reduces the toxicity as it is used in less concentration to kill the organisms [6]. Moreover, developing new antibiotics is very difficult, and thus only existing antibiotics should be used, and synergistic interactions play a major role in order to reduce the toxicity and make the organism susceptible to the resistance developed, which means it is trying to prevent the resistance. With the concern of previous lines, the synergism's main desire is that the increase in the effectiveness and reduces the toxicity and the blend of antibiotics and the natural compounds uprise the sensitivity of multiple drug-resistant bacteria and decline the minimum inhibitory concentration [7]. The organisms had multiple targets that had changed in order to develop the resistance. The plant or the herbal drugs and their extracted phytochemicals have been shown to target these multiple sites [6]. Say, for instance, thymol and carvacrol improve the porousness, epigallocatechin gallate (EGCG) represses beta-lactamases, EGCG, and reserpine hinders the bacterial efflux siphons or the pumps [8].

The most utilized antimicrobials such as penicillin, vancomycin, antibiotic medications, cephalosporins, and daptomycin were gotten from the normal sources [9]. The change of new advancements like genomic advances, high throughput screening assays, and combinatorial science to distinguish or find the new particle or the medication against the antimicrobial obstruction yet also use these atoms or the medication is unobtrusive. The main reason and the major focus would be on the target identification and the interaction of the drug molecule with the target, say enzymes or receptors; it is done instead of piercing the bacterial cell wall, which is done to avoid the mutation and avoid the efflux pumps. Thus, this had become the trend for studies and spotlighted natural compounds and screening of the new antimicrobials, which could potentially act in the organisms [10]. New tools have been utilized for the revelation and segregation of mixes from normal assets. The change in the structure makes them effective both chemically and biologically. Antimicrobials that are available naturally have been screened so far in the plant-based products by the pharmaceutical companies, and other natural resources are unchecked, say bacteria, fungi, actinomycetes, and insects like cockroach because they are profoundly exposed to the polluted environments, which makes them as a source of antimicrobials [11]. The main asset here is that they have declined side effects rather than the synthetically prepared drug [6]. Thus, now the researchers are working on natural products to find the new drugs [12].

\section{Synergistic Interactions between Phyto-Chemicals and Antimicrobial Drugs}

The synergistic interaction of phytochemicals with the antimicrobials or the antibiotics and the other majorly used clinical drugs has been taken to study them for the effective treatment of infections against multiple drug-resistant organisms. Here, the antibiotic and the phytochemicals are co-executed, which can avert the resistance. The plant extracts (crude) and the extracted compounds were tested [8]. The combo of natural products and antimicrobials has shown possibly an effective pharmacological derive [13]. For instance, plant compounds such as berberine and 5'-methoxyhydnocarpin, are usually found in barberry plants, displaying synergistic effects by focusing the intracellular part of the microorganisms and hindering the multiple drug resistance siphons [14]. A few different examinations in the synergism 
communication of the regular mixes and the antimicrobials state for an occurrence mix of curcumin with the EGCG saw in the multidrug safe life form Acinetobacter baumannii [15].

\section{Natural Plant-Based Products or Phyto-Chemicals Synergists as Inhibitors of Active Site Modification}

Certain organisms influence their cellular mechanisms to alter their targets, maybe enzymes or proteins or receptors, to care for themselves from the antibiotics or the antimicrobials. Thus, this change in the target makes them resistant to the antibiotics or the antimicrobial, which means they are unaffected and get through life. A very model is the elective penicillin-restricting protein (PBP2a) created by methicillin-safe S.aureus (MRSA), notwithstanding the "typical" penicillin-restricting proteins (PBPs) [16]. This amended gene is encoded by the mecA gene, and this had declined rapport for the beta-lactams, penicillin, and cephalosporins [17]. It is essential to restrain the change or adjusted dynamic site in these safe microorganisms, specifically PBP2a, that repress the antimicrobial from official to the microscopic organisms [6]. Say the excerpt of red rose, Rosa canina; it is found that it tends to decline minimum inhibitory concentrations of beta-lactams in Methicillin-Resistant S.aureus. Similarly, a compound called tellimagrandin I in synergism with the oxacillin and other betalactams. Tellimagrandin I reduced the least inhibitory groupings of beta-lactams by 128-512 creases. FIC file was 0.39 , indicating important synergism [18]. In other studies, phenolic compounds and the monosaccharides $\mathrm{B}$ have been shown to be active site inhibitors of PBP2a or PBP4, where they can be used as the synergistic antimicrobial beta-lactams against MRSA [19]. There are many synergistic combinations used in order to see the minimum inhibitory concentrations and to prevent the resistance in multiple drug resistance organisms and as well in making the decline in toxicity, say for example baicalin, a flavone, declined the minimum inhibitory concentrations of ampicillin, methicillin and cefotaxime in multiple drug-resistant $S$. aureus (MRSA) and as well in penicillin-resistant $S$. aureus and this can be further overburdened in overturning of the resistance [20].

\section{Natural Plant-Based Product or Phyto-Chemical in Synergism as Inhibitors Of Enzymes that Debase or Rework Drugs}

As previously stated, penicillin was the first antibiotic discovered that belongs to the beta-lactam class, and its overuse resulted in resistance. Here, the very basic and most important or huge case of microorganisms protects from antimicrobials is a construction of beta-lactamases that hydrolyzes or break down the classes of beta-lactams penicillin and cephalosporins. Over these years, 200 types of beta-lactamases were found in both Grampositive microscopic organisms and Gram-negative microorganisms. There are antibiotic betalactamases, for example, cephalosporinases which can hydrolyze cephalosporin, which is found in Enterobacter spp. the enzyme that degrades is AmpC enzymes, and the betalactamases can also hydrolyze these cephalosporins. To support this, an example would be penicillinases in $S$. aureus. If the target is going to be enzymes, the natural inhibitor that can be used is clavulanic acid, which is synergized with the antibiotics like penicillin for improved treatment outcomes [21]. The researchers delve into checking the plant crude extracts' efficiency for the advancement of unique beta-lactamase inhibitors [22]. To support this, the compounds are extracted and isolated from the Camellia sinensis (green tea) had exhibited the compound of beta-lactamases inhibitors. This compound has also shown the ability to reverse 
the resistant strains of $S$. aureus, which becomes vulnerable again, meaning sensitive to antibiotics [23].

\section{Natural Plant-Based Product or Phyto-Chemical Synergists as Inhibitors of Efflux Pumps}

Microorganisms can protect themselves from the action of antibiotics in them or pump out the antibiotic immediately or rapidly, making sure that they do not flow in. There is a decline in the antibiotics' action through the above, which made sure of the resistance in them [21]. For instance, the efflux coded by the msrA gene can pump out the erythromycin out of the cells, which is making them have decreased concentration in the cell and becoming resistant [24]. These efflux siphons are chromosomally encoded and have a place with the family opposition nodulation-division (RND) Gram-negative microbes. There are numerous efflux pumps described in $P$. aeruginosa, such as MexAB-OprM, MexXY-OprM, and so on. The significantly uncovered or communicated siphon is MexAB-OprM which is more adaptable and siphons out the anti-toxins without any problem. The antibiotics such as beta-lactams, tetracyclines, novobiocin, fluoroquinolones, and macrolides were failed in them [25]. To overcome this, effective efflux pump inhibitors must be used, such as Conessine, a steroidal alkaloid, inhibited the MexAB-OprM efflux pump in P. aeruginosa and made it susceptible to antibiotics [26]. The exact mechanism of efflux pump inhibitors is not known, and the other mechanism might be then the depletion of intensity or arrangement of a complex with antibiotics which helps to go inside the cells and bigger the size of the inhibitor better the stay and work of antibiotics inside the cells [27]. Several other synergy models are being studied and showed efficiency in inhibiting pumps such as Syringic acid and p-coumaric acid results in enhanced activity of and intracellular concentrations [28].

\section{Essential Oils Help in Synergism}

The essential oil was the term that was coined by Paracelsus, which implied the successful part of each medication called "quinta essentia" [29]. The essential oil components include terpenes, terpenoids, a long chain of hydrocarbons, or aliphatic and sweet-smelling mixes, for example, phenolic compounds and aldehydes [30]. The composition of essential oils is being determined by different elements like natural condition, the dirt determinants or creation, method or way of cultivation, season and season of the culling the plant, storage and preparing conditions like extraction and chemical method components analysis [31]. Essential oils are being extracted by many methods like refining maturation, pounding, extraction, airing, and hydrolysis, and the most successful technique is refining upon which steam refining is used. The chromatographic methods isolate a particular compound, and the most widely used technique among these is gas-chromatography-mass spectroscopy [32]. Apart from this, Thinlayer chromatography and High-performance Liquid Chromatography are utilized [33]. There is a wide range of utilization in fundamental oils like fixings in makeup, daycare items like scents, hair wash and in body salves, oral disinfectant arrangements and toothpaste and also in cleaning items for residential purposes and deodorizers and their certain bioactivities are antimicrobial, antioxidant, wound recuperating, anti-aging and so on [34]. Since they are considered the replenishing source and the emergence of antimicrobial resistance has been noticed to use them as the antimicrobial activity. Gram-positive microorganisms are more prone or susceptible to essential oils than Gram-negative microscopic structures [35], which is 
due to the membrane's impermeability, which acts as an authoritative hydrophilic character, giving cell membrane a shielding effect [36]. Gram-positive are more susceptible because their cell membrane is disrupted. There is inhibition of enzymes and disruption in ion channels [37], which leads to cellular death [38]. Huge attributes of the basic oils, such as hydrophobicity, aggravation of the cytoplasmic film, disturbance of the electron stream, dynamic vehicle, and coagulation of cell substance, can be considered potential systems of their antimicrobial activity [32]. The other mechanisms may be like dysfunction of membranes which contain the $\mathrm{pH}$ gradient and electrical conductance of the proton motive force [39]. The most efficient essential oil components are phenolic compounds which are carvacrol, eugenol, and thymol [40] which causes structural and functional changes in the cell [41]. The phenolic mixes like carvacrol indicated extraordinary inhibitory activities in life forms like L. monocytogenes and S. aureus, and the Gram-negative S. enteritidis, E. coli O157:H7, Y. enterocolitica, and Shigella flexneri [30]. These essential oils can also be used for synergistic interaction, which can show better results.

\section{Antimicrobial Peptides and their synergism}

Antimicrobial peptides are found in all classes of life. This is otherwise called the host safeguard peptides, which have been considered therapeutics for the antimicrobial obstruction lately because they assume a significant job in the natural insusceptible arrangement of the multicellular living beings [42]. In all circumstances, revealed normally happening and manufactured antimicrobial peptides are gathered in information bases, like Data Repository of Antimicrobial Peptides (DRAMP), which contains more than 4500 groupings of antimicrobial peptides [43]. They are classified into 4 classes depending on their auxiliary structures (i) $\alpha$-helical antimicrobial peptides (cathelicidins); (ii) $\beta$-sheet-containing antimicrobial peptides, regularly with at least two disulfide bonds present ( $\alpha$-and, $\beta$-defensins); (iii) Antimicrobial peptides with a $\beta$-clasp or circle adaptation settled by the nearness of a solitary disulfide bond as well as cyclization of the peptide chain (thanatin); (iv) short antimicrobial peptides with broadened compliances (indolicidin) [44].

As noted previously, antibiotics are ineffective against microorganisms that form biofilms, making it difficult for existing or conventional antibiotics to bring in the staticity of the organisms. To overcome this, synergism plays a role in bringing effectiveness and eradicating biofilms [45, 46]. As the significance of synergism is known already, which is lowering the dose concentration, increasing the effectiveness of antibiotics, and fewer side effects? For instance, checkerboard titration and stream cell tests exhibited that peptide 1018 synergized with sets of various classes of existing regular anti-toxins to turn away and remove existing biofilms yet when the peptide was enhanced within sight of low focus or levels of the antimicrobials ceftazidime, ciprofloxacin, imipenem, the grouping of anti-infection needed to evacuate biofilms was declined up to 64-overlap which included biofilms shaped by $P$. aeruginosa, E.coli, A. baumannii, K. pneumoniae, S. enterica and methicillin-resistant S.aureus [47].

The trouble in utilizing the antimicrobial peptide is that there is a decrease in their antimicrobial action amidst the organic liquids like serum and spit when contrasted with nonnatural conditions in phosphate supports. Because of the high convergences of salt, anionic proteins, and polysaccharides present in the organic liquids and inactivation of AMPs byhaving and bacterial proteases during the time of disease [48]. Antimicrobial peptides which are not from humans can damage human cells. For example, melittin, an alkaline polypeptide with 26 
amino acid residues derived from the venom of the European honeybee (Aphis mellifera), can break down or lyse cells, including erythrocytes.[49]. AMPs can also be prone to proteolytic degradation. With consideration of producing or making AMP is difficult and to get in large quantities because it involves the convoluted process of extraction, isolation, and purification [50]. Synergism contemplates, including AMPs are likewise basically expected to find fruitful AMP-AMP or AMP-sedate mixes to guarantee fewer reactions of these antimicrobials [51].

\section{Ways to Overcome Bacterial Resistance}

So far, it is seen how the microscopic structures can allay the drugs by methods of few systems such as classical or traditional mechanisms such as the modifications in the drug target, enzymatic inactivation, and the efflux pump. The other way of non-traditional or non-classical mechanistic way is the formation of biofilms. Hence, the plant-derived natural extracts and isolated compounds can be used to overcome the resistance [52].

\subsection{Clogging or filling of efflux pumps.}

Efflux pumps assume an essential job in the movement of the life forms. It helps in stress adaptation, virulence, and pathogenicity. They are considered one of the main sources for the development of antimicrobial resistance, so they must be targeted to prevent the resistance because they ensure pump-in of components and do not flow inside the cell. There are secondary metabolites or plant-based extracts which can potentially inhibit the pumps on the cell wall. Compounds such as catechol, piperine, quercetin, conessine, quercetin, epigallocatechin gallate and resveratrol [53-55]. The exact mechanism is not known well, but some of the phytochemicals molecules are clogged to inhibit the efflux pump. For example, totarol, a diterpene from Podocarpus totara, goes about as a simultaneous inhibitor of NorAsiphon in S. aureus [56]. Apart from this, polyphenolic compounds can directly attach to the pump and make structural conformation changes, thus inhibiting the pump [57]. The synergistic association can effectively focus on the pump and restrain it; for instance, alkaloid reserpine from Rauvolfia vomitoria hinders NorA efflux siphon action in $S$. aureus in a mix with fluoroquinolones [58].

\subsection{Constriction of bacterial harmfulness.}

In barely any cases, the plant inferred parts show their antibacterial action by intruding on the key pathogenic cycle. For instance, routine with sub-inhibitory groupings of thymol or eugenol declined the development of $\alpha$-hemolysin and Staphylococcal enterotoxins A and B in both methicillin-touchy and methicillin-safe S.aureus strains or disengages [59]. Similar results were obtained when using different compounds like allicin [60], alkaloid capsaicin, flavonoids, farrerol [61], and epicatechin gallate [62].

\subsection{Interruption in biofilms.}

The formation of bacterial biofilms is one such feature where the organism tries to protect itself from unfavorable or undesirable conditions like change in the environment or even the selection pressure of drugs or the drug environment. They are complex in a structure where the commune of microorganisms is placed on a surface that is wrapped around by the biopolymer matrix. This provides mechanisms to perform intracellular communications. The phenomenal ability of the life forms to live inside the biofilm is that the nearness of continuing 
cells which has the postponed digestion, the separating limit of the framework which upset the medication stream in and the hereditary "participation" and common help of bacterial cells taking into consideration organism networks to deal with their life assets and deftly reacts to the alterable ecological conditions. Biofilms that trigger or initiate the reason for constant, nosocomial, and clinical gadget-related diseases are the extraordinary danger in the center because of their high resistance to anti-infection agents [52]. Many studies have been done in order to disrupt the biofilm using secondary metabolites from plants like phenylpropanoids, terpenoids, betulinic and ursolic acids, alkaloids, and other plant-derived compounds were found to exhibit marked anti-biofilm activity against $P$. aeruginosa [63-67] $K$. pneumoniae [68, 69], Staphylococcal biofilms [70] which makes sure that the previously formed biofilms are also attacked, and as well there is the prevention of formation of new biofilms. Their interruption systems are accepted to be a disturbance in intracellular association, cell to cell coaggregation, immobilizing the cell portability, and inactivation of bond atoms [71].

\subsection{Blocking communication.}

Quorum sensing is one such mechanism where the microorganisms can communicate (cell-cell interaction). This would lead to new medication views on infections. Many plant extracts have been found to down-regulate the quorum-sensing gene expression in $P$. aeruginosa by organosulfur ajoene from garlic [72]. Two mechanisms have been stated in the inhibition of this process. Firstly, lowering the signaling molecules by down-regulating the quorum sensing genes and the interaction between the molecules of drug that is secondary plant metabolite with the signaling molecule quorum sensing thus deactivating the mediators and declining in cell intensity as well in communication [73].

\section{Conclusions}

In this review, the basic concept of synergism interaction of antimicrobials or the antibiotics with the combination of plant extracts or the individual components or phytochemicals is seen with the plant extracts and essential oils and as well as naturally occurring antimicrobial peptides and lastly, the overcome of antimicrobial resistance is seen. Plant extract for phytochemical drug combination shows auspicious results for the resistance modifying molecules or agents with various activities. For example, plant-based inferred mixes like EGCG synergistically intensify the antimicrobial movement of cell divider amalgamation inhibitors through the restraint of beta-lactamases. In a few many clinical trials, the plant extract and the synthetically prepared drugs were tested, and the results observed was that the natural extracts showed the significant result as like the synthetic drug whereas some showed superior effect with the already existing antimicrobial spectrum of drugs.

Since they are more efficient in treating the infection with low concentration and bringing in less toxicity and retrieving the sensitivity yet, they are not used much because of the use of plant molecules as a synergist and their mode of action needed to be known clearly. There are some cases where it can validate in vitro conditions, but it may not when coming to in vivo conditions. So these must be tested with controlled human trials. In the future, the potential antagonistic must be known generally and as well in organ pharmacology, meaning stating its adverse effect at organ level talking about the stability of the drug, toxicity, bioavailability, and interaction should be assessed as well. 
Thus, for the being, this method can be adapted to treat infections at critical conditions, and future applications needed to be found, say for example, in the field of transplantation and also treating any other medical conditions.

\section{Funding}

This research received no external funding.

\section{Acknowledgments}

The authors are thankful to B. S. Abdur Rahman Crescent Institute of Science and Technology, Vandalur, for providing research facilities in the School of Life Sciences.

\section{Conflicts of Interest}

The authors declare no conflict of interest.

\section{References}

1. McEwen, S.A.; Peter, J. Collignon. Antimicrobial resistance: a one health perspective. Antimicrob resis bac livestock compan anim 2018, 521-547, https://doi.org/10.1128/9781555819804.ch25.

2. Brinkac, L.; Voorhies, A.; Gomez, A.; Nelson, K.E. The threat of antimicrobial resistance on the human microbiome. Microbial Eco 2017, 74, 1001-1008, https://doi.org/10.1007/s00248-017-0985-z.

3. Yang, S.K.; Yusoff, K.; Mai, C.W.; Lim, W.M.; Yap, W.S.; Lim, S.H.E.; Lai, K.S. Additivity vs synergism: investigation of the additive interaction of cinnamon bark oil and meropenem in combinatory therapy. Mol 2017, 22, https://doi.org/10.3390/molecules22111733.

4. Borisy, A.A.; Elliott, P.J.; Hurst, N.W.; Lee, M.S.; Lehár, J.; Price, E.R.; Serbedzija, G.; Zimmermann, G.R.; Foley, M.A.; Stockwell, B.R.; Keith, C.T. Systematic discovery of multicomponent therapeutics. Proc Nat Acad Sci Uni Sta America 2003, 100, 7977-7982, https://doi.org/10.1073/pnas.1337088100.

5. Ayaz, M.; Ullah, F.; Sadiq, A.; Ullah, F.; Ovais, M.; Ahmed, J.; Devkota, H.P. Synergistic interactions of phytochemicals with antimicrobial agents: Potential strategy to counteract drug resistance. Chem bio interact 2019, 308, 294-303, https://doi.org/10.1016/j.cbi.2019.05.050.

6. Ayaz, M.; Sadiq, A.; Wadood, A.; Junaid, M.; Ullah, F.; Khan, N.Z. Cytotoxicity and molecular docking studies on phytosterols isolated from Polygonum hydropiper L. Steroids 2019, 141, 30-35, https://doi.org/10.1016/j.steroids.2018.11.005.

7. Stapleton, P.D.; Shah, S.; Anderson, J.C.; Hara, Y.; Hamilton-Miller, J.M.; Taylor, P.W. Modulation of $\beta-$ lactam resistance in Staphylococcus aureus by catechins and gallates. Int J Antimicrob Agents 2004, 23, 462467, https://doi.org/10.1016/j.ijantimicag.2003.09.027.

8. Hemaiswarya, S.; Kruthiventi, A.K.; Doble, M. Synergism between natural products and antibiotics against infectious diseases. Phytomed 2008, 15, 639-652, https://doi.org/10.1016/j.phymed.2008.06.008.

9. Monciardini, P.; Iorio, M.; Maffioli, S.; Sosio, M.; Donadio, S. Discovering new bioactive molecules from microbial sources. Microb Biotech 2014, 7, 209-220, https://doi.org/10.1111/1751-7915.12123.

10. Shah, S.M.; Ullah, F.; Ayaz, M.; Sadiq, A.; Hussain, S.; Shah, A.; Shah, S.A.A.; Ullah, N.; Ullah, F.; Ullah, I.; Nadhman, A. Benzoic acid derivatives of Ifloga spicata (Forssk.) Sch. Bip. as potential anti-Leishmanial against Leishmania tropica. Processes 2019, 7, https://doi.org/10.3390/pr7040208.

11. Lee, S.; Siddiqui, R.; Khan, N.A. Animals living in polluted environments are potential source of antimicrobials against infectious agents. Path Glob health 2012, 106, 218-223, https://doi.org/10.1179/2047773212Y.0000000033.

12. Ovais, M.; Khalil, A.T.; Islam, N.U.; Ahmad, I.; Ayaz, M.; Saravanan, M.; Shinwari, Z.K.; Mukherjee, S. Role of plant phytochemicals and microbial enzymes in biosynthesis of metallic nanoparticles. Appl Microb Biotech 2018, 102, 6799-6814, https://doi.org/10.1007/s00253-018-9146-7.

13. Cappiello, F.; Loffredo, M.R.; Del Plato, C.; Cammarone, S.; Casciaro, B.; Quaglio, D.; Mangoni, M.L.; Botta, B.; Ghirga, F. The revaluation of plant-derived terpenes to fight antibiotic-resistant infections. Antibio 2020, 9 , https://doi.org/10.3390/antibiotics9060325.

14. Stermitz, F.R.; Lorenz, P.; Tawara, J.N.; Zenewicz, L.A.; Lewis, K. Synergy in a medicinal plant: antimicrobial action of berberine potentiated by 5 '-methoxyhydnocarpin, a multidrug pump inhibitor. Proc Nat Aca Sci Uni Stat Amer 2000, 97, 1433-1437, https://doi.org/10.1073/pnas.030540597.

15. Betts, J.W.; Wareham, D.W. In vitro activity of curcumin in combination with epigallocatechin gallate (EGCG) versus multidrug-resistant Acinetobacter baumannii. BMC Microb 2014, 14, 1-5, https://doi.org/10.1186/1471-2180-14-172. 
16. Leonard, F.C.; Markey, B K. Meticillin-resistant Staphylococcus aureus in animals: a review. Vet J 2008, 175, 27-36, https://doi.org/10.1016/j.tvj1.2006.11.008.

17. Varela, M.C.; Roch, M.; Taglialegna, A.; Long, S.W.; Saavedra, M.O.; Rose, W.E.; Davis, J.J.; Hoffman, L.R.; Hernandez, R.E.; Rosato, R.R.; Rosato, A.E.; Carbapenems drive the collateral resistance to ceftaroline in cystic fibrosis patients with MRSA. Commun bio 2020 3, 1-10, https://doi.org/10.1038/s42003-02001313-5.

18. Shiota, S.; Shimizu, M.; Mizusima, T.; Ito, H.; Hatano, T.; Yoshida, T.; Tsuchiya, T. Restoration of effectiveness of $\beta$-lactams on methicillin-resistant Staphylococcus aureus by tellimagrandin I from rose red. FEMS Microbiol Lett 2000, 185, 135-138, https://doi.org/10.1111/j.1574-6968.2000.tb09051.x.

19. Kuok, C.F.; Hoi, S.O.; Hoi, C.F.; Chan, C.H.; Fong, I.H.; Ngok, C.K.; Meng, L.R.; Fong, P. Synergistic antibacterial effects of herbal extracts and antibiotics on methicillin-resistant Staphylococcus aureus: A computational and experimental study. Expt Biol Med 2017, 242, 731-743, https://doi.org/10.1177\%2F1535370216689828.

20. Liu, i.x.; Durham, D.G.; Richards, R.M.E.. Baicalin synergy with $\beta$ lactam antibiotics against methicillin resistant Staphylococcus aureus and other $\beta$ lactam resistant strains of S. aureus. J Pharm Pharmacol 2000, 52, 361-366, https://doi.org/10.1211/0022357001773922.

21. Livermore, D.M. Beta-Lactamases in laboratory and clinical resistance. Clin Microbiol Rev 1995, 8, 557584, https://doi.org/10.1128/CMR.8.4.557.

22. Neu, H.C.; Fu, K.P. Clavulanic acid. A novel inhibitor of $\beta$-lactamases. Antimicro Agents and Chemother 1978, 14, 650-655, https://doi.org/10.1128/AAC.14.5.650.

23. Álvarez-Martinez, F.J.; Barrajon-Catalan, E.; Encinar, J.A.; Rodriguez-Diaz, J.C.; Micol, V. Antimicrobial capacity of plant polyphenols against Gram-positive bacteria: A comprehensive review. Current medicinal chemistry 2020, 27, 2576-2606, https://doi.org/10.2174/0929867325666181008115650.

24. Abushaheen, M.A.; Fatani, A.J.; Alosaimi, M.; Mansy, W.; George, M.; Acharya, S.; Rathod, S.; Divakar, D.D.; Jhugroo, C.; Vellappally, S; Khan, A.A. Antimicrobial resistance, mechanisms and its clinical significance. Disease-a-Month 2020, 66, https://doi.org/10.1016/j.disamonth.2020.100971.

25. Poole, K. Pseudomonas aeruginosa: resistance to the max. Front Microbiol 2011, 2, https://doi.org/10.3389/fmicb.2011.00065.

26. Siriyong, T.; Srimanote, P.; Chusri, S.; Yingyongnarongkul, B.E.; Suaisom, C.; Tipmanee, V.; Voravuthikunchai, S.P. Conessine as a novel inhibitor of multidrug efflux pump systems in Pseudomonas aeruginosa. BMC complementary Altern Medicine 2017, 17, 1-7, https://doi.org/10.1186/s12906-017-1913y.

27. Holler, J.G.; Christensen, S.B.; Slotved, H.C.; Rasmussen, H.B.; Gúzman, A.; Olsen, C.E.; Petersen, B.; Molgaard, P. Novel inhibitory activity of the Staphylococcus aureus NorA efflux pump by a kaempferol rhamnoside isolated from Persea lingue Nees. J Antimicrob Chemother 2012, 67, 1138-1144, https://doi.org/10.1093/jac/dks005.

28. Nohynek, L.J.; Alakomi, H.L.; Kahkonen, M.P.; Heinonen, M.; Helander, I.M.; Oksman-Caldentey, K.M.; Puupponen-Pimia, R.H. Berry phenolics: antimicrobial properties and mechanisms of action against severe human pathogens. Nutr cancer 2006, 54, 18-32, https://doi.org/10.1207/s15327914nc5401_4.

29. Edris, A.E. Pharmaceutical and therapeutic potentials of essential oils and their individual volatile constituents: A Review. Phyto Res 2007, 21, 308-323, https://doi.org/10.1002/ptr.2072.

30. Dietz, C.; Cook, D.; Huismann, M.; Wilson, C.; Ford, R. The multisensory perception of hop essential oil: a review. J Inst of Brew 2020, 126, 320-342.

31. Wenndt, A.; Sudini, H.K.; Pingali, P.; Nelson, R. Exploring aflatoxin contamination and household-level exposure risk in diverse Indian food systems. PloS one 2020, 15, https://doi.org/10.1371/journal.pone.0240565.

32. Burt, S. Essential oils: their antibacterial properties and potential applications in foods. A Review. Int $J$ of food Microbiol 2004, 94, 223-253, https://doi.org/10.1016/j.ijfoodmicro.2004.03.022.

33. Dlamini, B.; Rangarajan, V.; Clarke, K.G. A simple thin layer chromatography based method for the quantitative analysis of biosurfactant surfactin vis-a-vis the presence of lipid and protein impurities in the processing liquid. Biocatal Agric Biotechnol 2020, 25, https://doi.org/10.1016/j.bcab.2020.101587.

34. Wallace, R.J. Antimicrobial properties of plant secondary metabolites. Proc Nutr Soc 2004, 63, 621-629, https://doi.org/10.1079/PNS2004393.

35. Cosentino, S.C.I.G.; Tuberoso, C.I.G.; Pisano, B.; Satta, M.L.; Mascia, V.; Arzedi, E. Palmas, F. In-vitro antimicrobial activity and chemical composition of Sardinian thymus essential oils. Lett Appl Microbiol 1999, 29, 130-135, https://doi.org/10.1046/j.1472-765X.1999.00605.x.

36. Smith-Palmer, A.; Stewart, J.; Fyfe, L. Antimicrobial properties of plant essential oils and essences against five important food-borne pathogens. Lett Appl Microbiol 1998, 26, 118-122, https://doi.org/10.1046/j.1472765x.1998.00303.x.

37. Dombach, J.L.; Quintana, J.L.; Nagy, T.A.; Wan, C.; Crooks, A.L.; Yu, H.; Su, C.C.; Yu, E.W.; Shen, J.; Detweiler, C.S. A small molecule that mitigates bacterial infection disrupts Gram-negative cell membranes and is inhibited by cholesterol and neutral lipids. PLoS Pathog 2020, 16, https://doi.org/10.1371/journal.ppat.1009119. 
38. Holley, R.A.; Patel, D. Improvement in shelf-life and safety of perishable foods by plant essential oils and smoke antimicrobials. Food Microbiol 2005, 22, 273-292, https://doi.org/10.1016/j.fm.2004.08.006.

39. Brown, T.P.; Ganapathy, V. Lactate/GPR81 signaling and proton motive force in cancer: Role in angiogenesis, immune escape, nutrition, and Warburg phenomenon. Pharmacology \& therapeutics 2020, 206, https://doi.org/10.1016/j.pharmthera.2019.107451.

40. Kachur, K.; Suntres, Z. The antibacterial properties of phenolic isomers, carvacrol and thymol. CRC Crit Rev Food Sci Nutr 2020, 60, 3042-3053, https://doi.org/10.1080/10408398.2019.1675585.

41. Walsh, S.E.; Maillard, J.Y.; Russell, A.D.; Catrenich, C.E.; Charbonneau, D.L.; Bartolo, R.G. Activity and mechanisms of action of selected biocidal agents on Gram positive and negative bacteria. J Appl Microbiol 2003, 94, 240-247, https://doi.org/10.1046/j.1365-2672.2003.01825.x.

42. Haney, E.F.; Mansour, S.C.;Hancock, R.E.. Antimicrobial peptides: an introduction. Antimicro Pep 2017, 322.

43. Fan, L.; Sun, J.; Zhou, M.; Zhou, J.; Lao, X.; Zheng, H.; Xu, H. DRAMP: a comprehensive data repository of antimicrobial peptides. Sci Rep 2016, 6, 1-7, https://doi.org/10.1038/srep24482.

44. Zasloff, M. Antimicrobial peptides of multicellular organisms. Nat 2002, 415, 389-395, https://doi.org/10.1038/415389a.

45. Bianchera, A.; Buttini, F.; Bettini, R. Micro/nanosystems and biomaterials for controlled delivery of antimicrobial and anti-biofilm agents. Expert Opin Ther Pat 2020, 1-18, https://doi.org/10.1080/13543776.2020.1839415.

46. Corrêa, R.C.; Heleno, S.A.; Alves, M.J. Ferreira, I.C. Bacterial Resistance: antibiotics of last generation used in clinical practice and the arise of natural products as new therapeutic alternatives. Current pharma des 2020, 26, 815-837, https://doi.org/10.2174/1381612826666200224105153.

47. Reffuveille, F.; De La Fuente-Nưnez, C.; Mansour, S.; Hancock, R.E. A broad-spectrum antibiofilm peptide enhances antibiotic action against bacterial biofilms. Antimicrob Agents and Chemother 2014, 58, 53635371, https://doi.org/10.1128/AAC.03163-14.

48. Bowdish, D.M.; Davidson, D.J.; Hancock, R. A re-evaluation of the role of host defence peptides in mammalian immunity. Curr Protein Pept Sci 2005, 6, 35-51, https://doi.org/10.2174/1389203053027494.

49. Tosteson, M.T.; Holmes, S.J.; Razin, M.; Tosteson, D.C. Melittin lysis of red cells. J membr biol 1985, 87, 35-44, https://doi.org/10.1007/BF01870697.

50. Gangathraprabhu, B.; Kannan, S.; Santhanam, G.; Suryadevara, N.; Maruthamuthu, M. A review on the origin of multidrug-resistant Salmonella and perspective of tailored phoP gene towards avirulence. Microbial Pathogenesis 2020, 147, https://doi.org/10.1016/j.micpath.2020.104352.

51. Jorge, P.; Lourenco, A.; Pereira, M.O. New trends in peptide-based anti-biofilm strategies: a review of recent achievements and bioinformatic approaches. Biofouling 2012, 28, 1033-1061, https://doi.org/10.1080/08927014.2012.728210.

52. Gorlenko, C.L.; Kiselev, H.Y.; Budanova, E.V.; Zamyatnin, A.A.; Ikryannikova, L.N. Plant Secondary Metabolites in the Battle of Drugs and Drug-Resistant Bacteria: New Heroes or Worse Clones of Antibiotics? Antibiotics 2020, 9, https://doi.org/10.3390/antibiotics9040170.

53. Kumar, R.; Pooja Patial, S.J. A review on efflux pump inhibitors of Gram-positive and Gram-negative bacteria from plant sources. Int $J$ Curr Microbiol Appl Sci 2016, 5, 834-855, http://dx.doi.org/10.20546/ijcmas.2016.506.092.

54. Gorlenko, C.L.; Kiselev, H.Y.; Budanova, E.V.; Zamyatnin, A.A.;Ikryannikova, L.N. Plant Secondary Metabolites in the Battle of Drugs and Drug-Resistant Bacteria: New Heroes or Worse Clones of Antibiotics? Antibiotics 2020, 9, https://doi.org/10.3390/antibiotics9040170.

55. Garvey, M.I.; Rahman, M.M.; Gibbons, S.;Piddock, L.J. Medicinal plant extracts with efflux inhibitory activity against Gram-negative bacteria. Int $J$ Antimicrob Agen 2011, 37, 145-151, https://doi.org/10.1016/j.ijantimicag.2010.10.027.

56. Bhaskar, B.V.; Babu, T.M.C.; Reddy, N.V.;Rajendra, W. Homology modeling, molecular dynamics, and virtual screening of NorA efflux pump inhibitors of Staphylococcus aureus. Drug Des Devel Ther 2016, 10, 3237-3252, https://dx.doi.org/10.2147\%2FDDDT.S113556.

57. Piddock, L.J.; Garvey, M.I.; Rahman, M.M.; Gibbons, S. Natural and synthetic compounds such as trimethoprim behave as inhibitors of efflux in Gram-negative bacteria. J Antimicrob Chemother 2010, 65, 1215-1223, https://doi.org/10.1093/jac/dkq079.

58. Stavri, M.; Piddock, L.J.; Gibbons, S. Bacterial efflux pump inhibitors from natural sources. J Antimicrob Chemother 2007, 59, 1247-1260, https://doi.org/10.1093/jac/dkl460.

59. Qiu, J.; Feng, H.; Lu, J.; Xiang, H.; Wang, D.; Dong, J.; Wang, J.; Wang, X.; Liu, J.; Deng, X. Eugenol reduces the expression of virulence-related exoproteins in Staphylococcus aureus. Appl Environ Microbiol 2010, 76, 5846-5851, https://doi.org/10.1128/AEM.00704-10.

60. Leng, B.F.; Qiu, J.Z.; Dai, X.H.; Dong, J.;Wang, J.F.; Luo, M.J.; Li, H.E.;Niu, X.D.;Zhang, Y.; Ai, Y.X.; Deng, X.M. Allicin reduces the production of $\alpha$-toxin by Staphylococcus aureus. Mol 2011, 16, 7958-7968, https://doi.org/10.3390/molecules16097958. 
61. Qiu, J.; Xiang, H.; Hu, C.; Wang, Q.; Dong, J.; Li, H.; Luo, M.;Wang, J.; Deng, X. Subinhibitory concentrations of farrerol reduce $\alpha$-toxin expression in Staphylococcus aureus. FEMS Microb Lett 2011, 315, 129-133, https://doi.org/10.1111/j.1574-6968.2010.02183.x.

62. Shah, S.; Stapleton, P.D.; Taylor, P.W. The polyphenol (-)-epicatechin gallate disrupts the secretion of virulence-related proteins by Staphylococcus aureus. Lett Appl Microb 2008 46, 181-185, https://doi.org/10.1111/j.1472-765X.2007.02296.x.

63. Lou, Z.; Letsididi, K.S.; Yu, F.; Pei, Z.;Wang, H.; Letsididi, R. Inhibitive effect of eugenol and its nanoemulsion on quorum sensing-mediated virulence factors and biofilm formation by Pseudomonas aeruginosa. J Food Prot 2019, 82, 379-389, https://doi.org/10.4315/0362-028X.JFP-18-196.

64. Xu, Z.; Zhang, H.; Yu, H.; Dai, Q.; Xiong, J.; Sheng, H.; Qiu, J.; Jiang, L.; Peng, J.; He, X.; Xin, R. Allicin inhibits Pseudomonas aeruginosa virulence by suppressing the rhl and pqs quorum-sensing systems. Can J Microbiol 2019, 65, 563-574, https://doi.org/10.1139/cjm-2019-0055.

65. Cho, H.S.; Lee, J.H.; Ryu, S.Y.; Joo, S.W.; Cho, M.H.; Lee, J. Inhibition of Pseudomonas aeruginosa and Escherichia coli O157: H7 biofilm formation by plant metabolite \&-viniferin. J Agric Food Chem 2013, 61, 7120-7126, https://doi.org/10.1021/jf4009313.

66. Koraichi Saad, I.; Hassan, L.; Ghizlane, Z.; Hind, M.; Adnane, R. Carvacrol and thymol components inhibiting Pseudomonas aeruginosa adherence and biofilm formation. Afr J Microbiol Res 2011, 5, 32293232, https://doi.org/10.5897/AJMR11.275.

67. Pattiyathanee, P.; Vilaichone, R.K.; Chaichanawongsaroj, N. Effect of curcumin on Helicobacter pylori biofilm formation. Afr J Biotechnol 2009, 8, 5106-5115.

68. Qian, W.; Sun, Z.; Wang, T.; Yang, M.; Liu, M.; Zhang, J.; Li, Y. Antimicrobial activity of eugenol against carbapenem-resistant Klebsiella pneumoniae and its effect on biofilms. Microb Pathog 2020, 139, https://doi.org/10.1016/j.micpath.2019.103924.

69. Magesh, H.; Kumar, A.;Alam, A.; Sekar, U. Identification of natural compounds which inhibit biofilm formation in clinical isolates of Klebsiella pneumoniae. Ind J exp biol 2013, 51, 764-72.

70. Morán, A.;Gutiérrez, S.; Martínez-Blanco, H.; Ferrero, M.A.; Monteagudo-Mera, A.; Rodríguez-Aparicio, L.B. Non-toxic plant metabolites regulate Staphylococcus viability and biofilm formation: a natural therapeutic strategy useful in the treatment and prevention of skin infections. Biofouling 2014, 30, 11751182, https://doi.org/10.1080/08927014.2014.976207.

71. Silva, L.N.; Zimmer, K.R.; Macedo, A.J.; Trentin, D.S. Plant natural products targeting bacterial virulence factors. Che Rev 2016, 116, 9162-9236, https://doi.org/10.1021/acs.chemrev.6b00184.

72. Jakobsen, T.H.; van Gennip, M.; Phipps, R.K.; Shanmugham, M.S.;Christensen, L.D.; Alhede, M.; Skindersoe, M.E.; Rasmussen, T.B.; Friedrich, K.; Uthe, F.; Jensen, P.Ø. Ajoene, a sulfur-rich molecule from garlic, inhibits genes controlled by quorum sensing. Antimicrob Agents Chemothe 2012, 56, 23142325, https://doi.org/10.1128/AAC.05919-11.

73. Kalia, V.C.; Patel, S.K.; Kang, Y.C.; Lee, J.K. Quorum sensing inhibitors as antipathogens: biotechnological applications. Biotechnol Adv 2019, 37, 68-90, https://doi.org/10.1016/j.biotechadv.2018.11.006. 